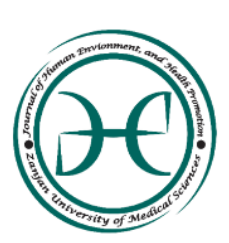

Journal of Human, Environment and Health Promotion

Journal homepage: www.zums.ac.ir/jhehp

\title{
Musculoskeletal Disorders and its Related Risk Factors among Students of Qazvin University of Medical Sciences
}

\section{Samira Ansari a, Morteza Rezapoor a, Mohammad Amin Hematgar a , Atiye Sadat Ghazi a, Sakineh Varmazyar ${ }^{a, *}$}

${ }^{a}$ Department of Occupational Health Engineering, Faculty of Health, Qazvin University of Medical Sciences, Qazvin, Iran.

*Corresponding author.E-mail address: Svarmazyar@qums.ac.ir

\section{A R T I C L E I N F O}

Article history:

Received March 5, 2017

Accepted April 22, 2017

Article Type:

Original Article

Keywords:

Musculoskeletal Disorders

Student

University

Nordic Questionnaire

\begin{abstract}
A B S T R A C T
Background: Since students spend a lot of time in classrooms and in steady state, many of them may experience signs of musculoskeletal disorders. The aim of this study was to determine the prevalence of musculoskeletal disorders and its related risk factors among students.

Methods: This descriptive-analytical and cross-sectional study was conducted among 129 students of Qazvin University of Medical Sciences in 2016. In order to determine the prevalence of musculoskeletal disorders, Nordic questionnaire was used. The relationship between musculoskeletal disorders and risk factors was evaluated in SPSS20 software.

Results: The highest incidence of musculoskeletal discomfort $(80 \%)$ was observed in the waist area. The neck $(38.3 \%)$ and shoulder $(35 \%)$ were the most prevalent at the next levels. Marital status, age, weight, educational level, job, exercise and stress were identified as risk factors affecting the musculoskeletal disorders in the students.

Conclusion: It is possible to reduce the prevalence of musculoskeletal disorders by the necessary trainings to declare the risk factors and their modifications to the students, considering appropriate time between the classes and the use of ergonomic equipment and furniture in the classes. With these actions also can prevent from stress and consequently can increase the concentration and learning power in this group.
\end{abstract}

\section{Introduction}

The university is one of the communities that can be used to prepare students for coping with the problems of the community. So that achieving this important goal is possible in the light of effective teaching in a stress-free environment [1]. In fact, universities are the workplace of students, and students spend most of their time attending a university in classrooms and sit in a sitting position [2-4]. Therefore, they are at risk of various factors associated with long-term sedentary position and poor and static postures [3].

Also, in past studies, the relationship between undesirable postures with cognitive problems, as well as the level of consciousness, discomfort, and the time taken for the person's response have been verified. Many people are consciously or unknowingly adapting to their perineal environment, some of which, if maintained for a

To cite: Ansari S, Rezapoor M, Hematgar MA, Ghazi AS, Varmazyar S. Musculoskeletal Disorders and its Related Risk Factors among Students of Qazvin University of Medical Sciences. J Hum Environ Health Promot. 2017; 2(3):161-167. 
long time, cause local stress on tissues and organs [5]. Static posture and long-term sitting cause damage to the spine due to decreased disk nutrition, limiting blood flow and increased muscle tiredness, resulting in decreased elasticity and softness of the intervertebral discs [6], As well as severe physiological stress on the muscles and ligaments $[7,8]$.

Musculoskeletal disorders are defined as any damage to the muscular and nervous system including muscles, bones, ligaments, tendons, and blood vessels [9]. This disorders can affect the ability, efficiency and effectiveness, well-being, productivity, absence from work, quality of work, and performance of individuals $[10,11]$, as well as leading to create restrictions on the normal activities of students $[12,13]$. Unlike many work related disorders, musculoskeletal disorders are often multifactorial and physical, psychosocial, organizational and individual factors and work environment are from risk factors of these disorders [14]. Psychosocial factors can include work pressures and job dissatisfaction. According to recent studies, musculoskeletal disorders in addition to ergonomic exposures, depends on demographic factors such as age, sex, BMI and anthropometry and also other factor such as time, muscular strength, anthropometry, mental stresses and etc [15-18]. Also musculoskeletal pains are strongly associated with adverse psychological factors of working environment [19].

Shokri (2015) reported the most common incidence of discomfort among students in shoulder, neck and lower back segments. In this study, sex was one of the factors affecting the incidence of musculoskeletal disorders in students [20]. In Kazemi's research (2017), there was a high prevalence of pain in the back and knees in dormitory students [21].

Since students spend a lot of time in classrooms in stationary situations, many can be expected to experience signs of musculoskeletal disorders.

Based on current statistics, more than 4,400,000 students are studying in our country, so the health of this group of society is very important [22].

Due to the lack of study among the Iranian students and the important role of this group in society, the aim of this study was to determine the prevalence of musculoskeletal injuries in different areas of the body and the factors affecting their incidence in students.

\section{Materials and Methods}

This research is a descriptive-analytic study that was conducted on a cross-sectional basis in 2016 among students of Qazvin University of Medical Sciences. According to previous study (1) and Equation 1 with $5 \%$ error, the number of sample was estimated to be 133 that in this study 129 students were conducted.

$N=\frac{p(1-p) Z^{2}}{d^{2}}$

Students were randomly selected and a Nordic standard questionnaire was used to determine the prevalence of musculoskeletal discomfort. The questionnaire has two parts, one part of which is demographic information, and the second part is related to disturbance in different areas of the body. The questionnaire was designed in 1987 by Kuorinka et al. In the Scandinavian Institute of Occupational Health, and its validity and reliability have been confirmed [23]. Finally, the data obtained from the questionnaire were entered into the SPSS software version 20. Using descriptive statistics and Phi and Cramer's V test, the relationship between the prevalence of musculoskeletal disorders and its related factors was examined.

\section{Results and Discussion}

Based on the findings of this study, the mean and standard deviation of age was $20.74 \pm 2.31$ years. The mean and standard deviation of height and weight of participants in the study were 169.1 \pm 9.09 and $63.9 \pm 12.73 \mathrm{~kg}$, respectively. The mean and standard deviation of the class time per week was also $17.1 \pm 4.56$ hours. $74.4 \%$ of the study group was female and $25.6 \%$ male, $89.1 \%$ were single and $10.9 \%$ were married. Also, the students studied were from different fields of health $(65.2 \%)$ and paramedical $(34.8 \%)$ and different degrees of qualification (8.5\%), undergraduate $(89.9 \%)$ and masters $(1.6 \%)$ were 
chosen. The percentage of background and underlying information provided by the participating students is presented (Table 1).

Table 1: Frequency of background information for participants $(\mathrm{n}=129)$.

\begin{tabular}{lcc}
\hline \multicolumn{1}{c}{ Frequency } & Categories & Information \\
\hline Job & Yes & 17.1 \\
The habit of & Left hand & 82.9 \\
Writing & Right hand & 6.2 \\
Sport Activities & Yes & 93.8 \\
& No & 54.3 \\
Stress & Yes & 45.7 \\
& No & 48.1 \\
Underlying & Yes & 51.9 \\
Diseases & No & 0.8 \\
& Yes & 99.2 \\
Neurovascular & No & 3.1 \\
disorders & Yes & 96.9 \\
Disquiet & No & 38 \\
& & 62 \\
\hline
\end{tabular}

The prevalence of musculoskeletal disorders in different areas of the body is shown in Fig. 1 on the students. This chart shows that the highest incidence of musculoskeletal discomfort is in students in the waist (80\%). Then, in the next ranges, the neck and shoulders were the highest prevalence.

Among the variables studied, there was a significant and negative correlation between sex with height and weight. As a result, male students had a higher height and weight $(\mathrm{p}=0.000, \mathrm{r}=$ $0.648, \mathrm{r}=-0.558)$.

The relationship between the variables studied and the incidence of discomfort in different areas of the body is presented (Table 2). Variables not listed in the table had no meaningful correlation with the discomfort of any of the areas in the body. In particular, it can be said that gender, height, field and academic term, left or right hand are factors that have no effect on the incidence of pain in different areas of the body.

Musculoskeletal disorders are often caused by inappropriate conditions in the surrounding environment. Musculoskeletal problems impose significant economic costs on health and indirectly affect the productivity of people [15]. The first step in the prevention, is diagnosis and treatment of musculoskeletal disorders, determine the prevalence and pattern of these disorders, so that appropriate corrective action can be identified and implemented on this basis. In this study, the highest prevalence of musculoskeletal disorders was reported in the waist, neck and shoulder. In the study of Zarei and Hosseini, the highest incidence of discomfort was in the waist of students [1, 22]. In the studied Shruti and Whittfield, the most common incidence of discomfort among students was reported in the neck and shoulders [24, 25]. Static and long-term sitting, regardless of time for rest, can lead to increased muscle tension and fatigue in people. It can also be a cause of pain and in the long term and in the absence of ergonomic principles, it can lead to an increase in the incidence of musculoskeletal disorders. In examining the relationship between the prevalence of musculoskeletal disorders and the demographic and individual variables of the subjects, it was determined that marital status, age, weight, educational level, occupation, exercise, and stress in the classroom are from the factors that each of them have a significant relationship with incidence of discomfort in a particular part of the musculoskeletal system.

The marital status was significantly correlated with incidence of discomfort in the neck, knees and stalks in students. Also, the relationship between age and the incidence of discomfort in the shoulder, arm, wrists and hip was significant, which is consistent with the study of Choobineh [26]. In the study of Hosseini et al, There was no significant relationship between age and prevalence of musculoskeletal disorders [22].

Gender did not show a significant relationship with the prevalence of pain in any areas of the body, which has been confirmed in the studies of 
Ataei and Hosseini $[10,22]$. In the study of Shokri [20], Ekman [27], Kerosuo [28] and Karlqvist [29], it was shown that there is a significant difference between the incidence of musculoskeletal discomfort in men and women, which contradicts the results of this study. For the opposite reason, these studies have been conducted among computer users and dentists.

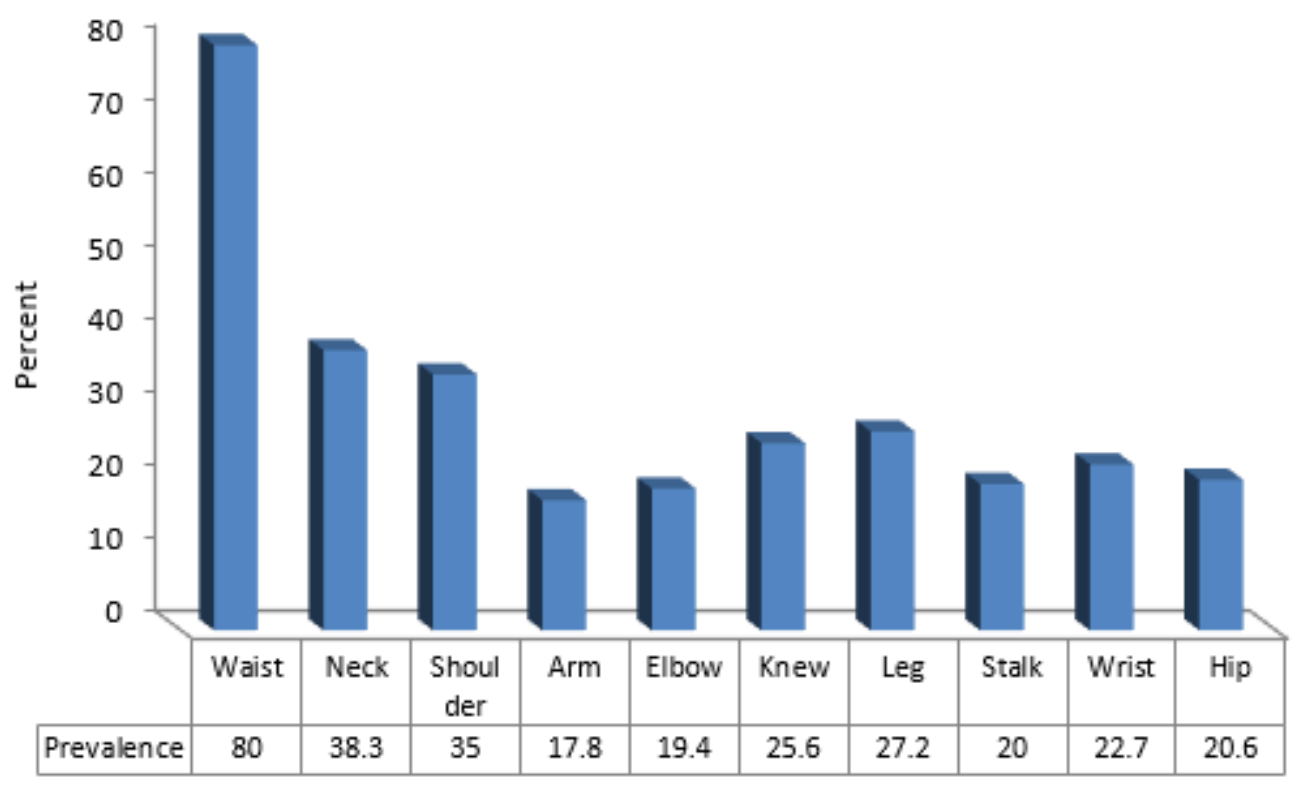

Fig. 1: Prevalence of musculoskeletal disorders in different areas of body.

Table 2: Investigating the relationship between variables with prevalence in different areas of the body.

\begin{tabular}{lccccccccccc}
\hline $\begin{array}{c}\text { Variable } \\
\text { Body } \\
\text { areas }\end{array}$ & $\begin{array}{c}\text { Marital } \\
\text { Status }\end{array}$ & Age & Weight & $\begin{array}{c}\text { Educational } \\
\text { section }\end{array}$ & $\begin{array}{c}\text { Having } \\
\text { a job }\end{array}$ & Sport & Stress & $\begin{array}{c}\text { Going } \\
\text { to the } \\
\text { doctor }\end{array}$ & Absence & Disquiet \\
\hline Waist & 0.437 & 0.175 & $0.049 *$ & 0.923 & 0.093 & 0.354 & $* 0.013$ & $0.027 *$ & $0.04 *$ & $* * 0.000$ \\
Neck & $0.002 * *$ & 0.136 & 0.101 & $0.043 *$ & 0.947 & 0.33 & 0.305 & $0.011^{*}$ & 0.654 & $* * 0.000$ \\
Shoulder & 0.575 & $0.007 * *$ & 0.49 & 0.84 & 0.091 & 0.629 & 0.237 & $0.01 * *$ & 0.655 & $* 0.025$ \\
Arm & 0.139 & $0.043^{*}$ & 0.85 & 0.335 & 0.338 & 0.601 & 0.052 & $0.016^{*}$ & 0.179 & $* 0.012$ \\
Elbow & 0.752 & 0.162 & 0.193 & 0.09 & 0.674 & 0.321 & 0.073 & $0.038^{*}$ & 0.239 & 0.055 \\
Knee & $0.02 *$ & 0.361 & 0.668 & 0.404 & 0.443 & $* 0.032$ & 0.609 & 0.106 & 0.423 & $* 0.033$ \\
Leg & 0.721 & 0.442 & 0.364 & 0.972 & 0.392 & 0.73 & 0.184 & 0.129 & 0.571 & 0.14 \\
Stalk & $0.014 *$ & 0.075 & 0.8 & 0.721 & 0.95 & 0.346 & $* 0.029$ & $0.014 *$ & 0.331 & $* * 0.006$ \\
Wrist & 0.553 & $0.003 * *$ & 0.563 & 0.66 & $* 0.013$ & 0.432 & 0.351 & $0.026 *$ & $0.003 * *$ & $* * 0.005$ \\
Hip & 0.222 & $0.034 *$ & 0.553 & 0.548 & 0.223 & 0.14 & 0.096 & 0.977 & $0.006 * *$ & $* 0.014$ \\
\hline
\end{tabular}

**significance in 0.01

Weight only showed a significant relationship with the incidence of waist discomfort. In some *significance in 0.05

studies, there was no significant correlation between weight with discomfort in any areas of 
the body [10, 22]. In the study of Choobineh, there was a significant correlation between weight and the prevalence of musculoskeletal disorders [26].

In the study of Farouresh, weight only showed a significant relationship with the incidence of discomfort in the elbow and knee, while in the present study, weight was only associated with the incidence of waist discomfort [30]. Height also did not show a significant relationship with the incidence of discomfort in any areas of the body, which is similar to the study of Hosseini and Ataei $[10,22]$.

A significant relationship was found between the incidence of musculoskeletal discomfort in the neck and educational level and having a job with only wrist discomfort. In Hosseini's study, there was no significant relationship between the educational level and the incidence of discomfort,

which is due to the low prevalence of discomfort. Also, in the Hosseini's Study, there was no significant relationship between the field of study and the incidence of discomfort, which is consistent with the present study [22].

There was no significant relationship between age and exercise with the prevalence of musculoskeletal disorders in a study by Miri [31].

The reasons for the inconsistencies between the various studies with this study can be attributed to the difference in the sample group in these studies and even to the differences in age and sex groups.

The habit of writing did not show a meaningful relationship with the incidence of discomfort in any area of the body. In the study of Ahmadi Motemayel, there was also no significant relationship between left and right handedness and discomfort in any organs of the body [32]. Stress is one of the factors affecting the incidence of discomfort in the waist and stalks. Also, there was a significant and positive correlation between discomfort in the waist, shoulder, neck, arm, knees, stalks, wrists and hip, with degree of disquiet in the class. So the presence of these disorders in the musculoskeletal system of students leads to stress and disquiet in them and reduces the concentration and the power of learning in them. Also, according to the results, the prevalence of musculoskeletal discomfort in some parts of the body, such as waist and wrists, showed a significant relationship with the number of visits to the doctor and absence from the class.

In many cases, the prevalence of pain in different parts of the body has led to an increase in the number of visits to the doctor and the absence from classrooms in the students. Considering the high prevalence of musculoskeletal disorders in students and the effect of different factors on the prevalence of these discomforts, measures should be taken to reduce the prevalence of musculoskeletal disorders and even control the factors affecting them.

\section{Conclusion}

By implementing the necessary trainings to declare these risk factors and their modifications to the students, considering the appropriate intervals between the classrooms to rest and change the position as well as the dynamic movements, the use of ergonomic equipment and furniture in classes and actions of this kind can, to a large extent, reduce the prevalence of musculoskeletal disorders in students and indirectly prevent stress and consequently increase the concentration and learning ability of this group. No considering of some risk factors of musculoskeletal disorders in students such as body posture is one of the limitations of this study. So, it is suggested that the posture of students be evaluated by appropriate risk assessment methods.

Also it is suggested that this study to perform in all faculties of the university that have different conditions of ergonomic.

\section{References}

1. Zarei F, Vafaei B, Nikpey A, Varmazyar S, Safari-Variani A. Review the Proportion of University Seats with Body Dimensions of Students at the School of Public Health of Qazvin University of Medical Sciences in 1388. J Iran Occup Health. 2011; 8(3): 39-47. 
2. Agha SR, Alnahhal MJ. Neural Network and Multiple Linear Regression to Predict School Children Dimensions for Ergonomic School Furniture Design. J Appl Ergon. 2012; 43(6): 97984.

3. Dianat I, Karimi MA, Hashemi AA, Bahrampour S. Classroom Furniture and Anthropometric Characteristics of Iranian High School Students: Proposed Dimensions Based on Anthropometric Data. J Appl Ergon. 2013; 44(1): 101-8.

4. Taifa IW, Desai DA. Anthropometric Measurements for Ergonomic Design of Students' Furniture in India. Eng Sci Tech, Int J. 2017; 20(1): 232-9.

5. Abedi M. An Evaluation of Combined Effect's of Backrest Inclination and Whole Body Vibration on Vehicle Driver's Reaction Time and Workload. MSc Thesis. 2011.

6. Holm S, Nachemson A. Variations in the Nutrition of the Canine Intervertebral Disc Induced by Motion. J Spine. 1983; 8(8): 866-74.

7. Panagiotopoulou G, Christoulas K, Papanckolaou A, Mandroukas K. Classroom Furniture Dimensions and Anthropometric Measures in Primary School. J Appl Ergon. 2004; 35(2): 121-8.

8. Bendix T. Adjusment of the Seated Workplace with Special Reference to Heights and Inclinations of Seat and Table. Dan Med Bull. 1987; 34(3): 125-39.

9. Mirzaei R, Moussavi Najarkola SA, Asadi Khanoki B, Ansari H. Comparative Assessment of Upper Limbs Musculoskeletal Disorders by Rapid Upper Limb Assessment Among Computer Users of Zahedan Universities. J Health Scope. 2014; 3(4): e15226.

10. Ataei S, Heydari P, Varmazyar S. Investigation of Correlation of Musculoskeletal Disorders with Work Ability Index and Allowable Load Lifting Limit. J Ergon. 2017; 4(4): 14-23.
11. Moussavi-Najarkola SA, Mirzaei R. Assessment of Musculoskeletal Loads of Electric Factory Workers by Rapid Entire Body Assessment. J Health Scope. 2012; 1(2): 71-9.

12. Choobine A, Soleimaninejad E, Daneshmandi H, Mohammadbeigi A, Izadi Kh. The Prevalence of Musculoskeletal Disorders and Postural Assessment by Rula Method in General Dentists in Shiraz in 1389. Izadi KH Dentistry. 2012; 24(4): 310-17.

13. Seifi S, Eftekharian Sh, Sarrafan N, Gholinia H. Ergonomic Evaluation of Frequency and Risk Factors of Musculoskeletal Disorder of Specialist Dentists of Babol Dentistry Faculty. J Urmia Univ Med Sci. 2016; 27(4): 330-5.

14. Mohammadfam I, Kianfar A, Afsartala B. Assessment of Musculoskeletal Disorders in a Manufacturing Company Using Qec and Luba Methods and Comparison of Results. J Iran Occup Health. 2010; 7(1): 54-60.

15. Jafari Nedoshan R, Halvani Gh, Vatani Shoa J, Salmani Nedoshan Z. Investigation of Musduloskeletal Disorders in Staffs of Bank in Yazd. J Work Med Q. 2011; 3(1): 1-7.

16. David G, Woods V, Li G, Buckle P. The Development of the Quick Exposure Check (Qec) for Assessing Exposure to Risk Factors for WorkRelated Musculoskeletal Disorders. J Appl Erg. 2008; 39: 57-39.

17. Bolghanabadi S, Pour M. The Relationship between Musculoskeletal Disorders, Stress and Fatigue in the Food Industry Employees. J Ergon. 2014; 2(1): 54-63.

18. Koo H-R, Shin Y-S, Chae H-S, Lee K-S. The Research of Job Stress and MSDs Symptoms of Small Plants with Agricultural Products. J Agric Ext \& Community Dev. 2011; 18(4): 861-77.

19. Haukka E, Ojajärvi A, Takala E-P, ViikariJuntura E, Leino-Arjas P. Physical Workload, Leisure-Time Physical Activity, Obesity and Smoking as Predictors of Multisite Musculoskeletal Pain. A 2-Year Prospective Study 
of Kitchen Workers. J Occup Environ Med. 2012; 69(7): 485-92.

20. Shokri S, Ghalenoei M, Taban E, Ahmadi O, Kouhnavard B. Evaluation of Prevalence of Musculoskeletal Disorders among Students Using Portable Computer in Faculty of Health, Qazvin University of Medical Sciences. J Health Res Community. 2015; 1(3): 9-15.

21. Kazemi S, Rafighi M. Investigation the Musculoskeletal Disorders in Students of Dormitories of Tarbiat Modares University. $10^{\text {th }}$ University Students Conference on Innovations in Health Sciences. 2017.

22. Hosseini $\mathrm{MH}$, Khodadadi $\mathrm{M}$, Hoshiar $\mathrm{H}$, Noorbakhsh AH. The Effect of Different Classroom Chairs on the Prevalence of Musculoskeletal Problems and the Rate of Students' Satisfaction. J Health Dev. 2015; 4(3): 209-18.

23. Kuorinka I, Jonsson B, Kilbom A, Vinterberg $\mathrm{H}$, Biering Sørensen F, Andersson G, et al. Standardized Nordic Questionnaires for the Analysis of Musculoskeletal Symptoms. J Appl Ergon. 1987; 18(233-7).

24. Iyer Shruti R. An Ergonomic Study of Chronic Musculoskeletal Pain in Schoolchildren. Indian J Pediatr. 2001; 68(10): 937-41.

25. Whittfield J, Legg S, Hedderley D. The Weight and Use of Schoolbags in New Zealand Secondary Schools. J Ergon. 2001; 44(9): 819-24.

26. Choobineh A, Rahimi Fard H, Jahangiri M, Mahmood Khani S. Musculoskeletal Injuries and Their Associated Risk Factors. J Iran Occup Health. 2012; 8(4):70-81.

27. Ekman A, Andersson A, Hagberg M, Hjelm E. Gender Differences in Musculoskeletal Health of Computer and Mouse Users in the Swedish Workforce. J Occup Med. 2000; 50(8): 608-13.

28. Kerosuo E, Kerosuo H, Kanerva L. SelfReported Health Complaints among General Dental Practitioners, Orthodontists, and Office
Employees. Acta Odonto Scand. 2000; 58(5): 20712.

29. Karlqvist L, Tornqvist EW, Hagberg $M$, Hagman M, Toomingas A. Self-Reported Working Conditions of VDU Operators and Associations with Musculoskeletal Symptoms: A CrossSectional Study Focusing on Gender Differences. Int J Ind Ergon. 2002; 30(4): 277-94.

30. Farouresh E, Mazloumi A, Habibi M. Ergonomics Evaluation of Body Postures and Effective Risk Factors Contributing Musculoskeletal Disorder in Barbers in Sardasht. Jhsw. 2012; 1(2): 45-50.

31. Miri M, Hosseini M, Sharifzade GH. Ergonomic Assessment of Working Conditions in Birjand Hairdressers in Reba Method. J Gonabad Univ Med Sci. 2009; 14(2): 39-44.

32. Ahmadi Motemayel F, Abdolsamadi $\mathrm{H}$, Roshanaei G, Jalilian S. Prevalence of Musculoskeletal Disorders among Hamadan General Dental Practitioners. Sci J Hamadan Univ Med Sci. 2012; 19(3): 61-6. 